\title{
Physiological and environmental control of seed germination timing in Mediterranean mountain populations of Gundelia tournefortii
}

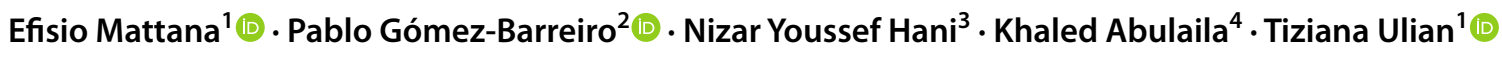

Received: 23 January 2021 / Accepted: 29 April 2021 / Published online: 22 May 2021

(c) The Author(s) 2021

\begin{abstract}
Fruit and seed morphology interact with embryo physiology and environmental conditions to control seed germination timing. This interaction plays a pivotal role in ecosystems with narrow windows for seedling establishment, such as the Mediterranean mountains. In this study, we investigated the germination responses of the secondary capitula (disseminules) of Gundelia tournefortii from East Mediterranean mountain populations. When incubated at $15{ }^{\circ} \mathrm{C}$, intact capitula did not reach $20 \%$ of final germination, with or without the addition in the germination substrate of $\mathrm{GA}_{3}\left(250 \mathrm{mg} \mathrm{L}^{-1}\right)$, while extracted fruits reached $50 \%$ of germination, which increased to ca. $70 \%$ when treated with $\mathrm{GA}_{3}$. Cold stratification enhanced final germination of the capitula at $15^{\circ} \mathrm{C}$ to ca. $65 \%$, although almost half of the initially sown capitula germinated during the second month of stratification at $5{ }^{\circ} \mathrm{C}$. During the stratification at $5{ }^{\circ} \mathrm{C}$, peak puncture force needed to pierce the basal part of the capitula decreased linearly and capitula started germinating after one month, which corresponded to a peak puncture force of $0.41-0.35 \mathrm{~N}$. These findings highlight the presence of mechanical and hormonal components of physiological seed dormancy. The morphology of the disseminules controls seed germination timing, by interacting with cold winter temperatures and starting seed germination only in early winter. These findings not only provide new insights on the reproduction from seeds of this plant, but by highlighting high germination of cold-stratified intact capitula, can also support plant propagation programmes for this key wild edible species, very important for food security and the livelihoods of local communities in the East Mediterranean region.
\end{abstract}

Keywords Cold stratification $\cdot$ Dispersal unit $\cdot$ Mechanical constraint $\cdot$ Puncture force $\cdot$ Seed dormancy $\cdot$ Wild edible plant

\section{Introduction}

Seeds are the main means through which flowering plants can move in space and in time (Chen et al. 2020; Poschlod et al. 2013). There is a wide diversity in the type of dispersal

Communicated by Shubhpriya Gupta.

Efisio Mattana

e.mattana@kew.org

1 Natural Capital and Plant Health Department, Royal Botanic Gardens, Kew, Wakehurst, Ardingly RH17 6TN, West Sussex, UK

2 Analytical Methods Department, Royal Botanic Gardens, Kew, Wakehurst, Ardingly RH17 6TN, West Sussex, UK

3 Shouf Biosphere Reserve (SBR), Park house, El Shouf, Maasser El Shouf, Lebanon

4 National Agricultural Research Center (NARC), PO Box 639, Baqa'a 19381, Jordan units among angiosperms, including true seeds, whole fruits and part of fruits (e.g. endocarps or mericarps). In the particular case of tumbleweeds, the entire plant (or at least the above ground portion) is dispersed by wind in open habitats, with seeds still attached to the plant (Poschlod et al. 2013). At the same time, diversity in fruit and seed morphology provides biomechanical and physiological adaptations that shape reproductive performance (Sperber et al. 2017; Steinbrecher and Leubner-Metzger 2016) and interacts with environmental conditions to ensure seed dormancy breaking and/or germination occurs in the most favourable timing for seedling establishment (Baskin and Baskin 2014). In some seeds with physiological dormancy whose embryo growth is mechanically constrained by mostly dead seed-covering layers such as the outer testa or pericarp, the completion of germination requires either an increase of the embryo growth potential (hormonal constraint) and/or a reduction of the mechanical constraint associated with the seed-covering layer(s) (Finch-Savage and Leubner-Metzger 2006). 
High Mediterranean mountains represent an ecological link between lowland Mediterranean sclerophyllous and alpine mesophylous ecosystems when considering plant reproduction from seeds (Giménez-Benavides et al. 2005; Picciau et al. 2019). Overwintering and warm-cued germination are key drivers of germination in alpine habitats, with the interplay between germination physiology and seed morphological traits further reflecting pressures to avoid frost or drought stress (Fernández-Pascual et al. 2021). On the contrary, the typical "Mediterranean germination syndrome" of lowland species/populations is characterized by a coldcued germination, limiting germination window to autumn/ winter, therefore maximising the length of the growing season, before the onset of summer drought (Doussi and Thanos 2002; Thanos et al. 1989, 1991, 1995). However, seeds of Mediterranean mountain species/populations germinate at higher incubation temperatures than the lowland ones (Giménez-Benavides et al. 2005; Picciau et al. 2019). Nevertheless, seeds of a high number of Mediterranean mountain species are non-dormant at dispersal and can germinate without any pre-treatment (Giménez-Benavides et al. 2005; Lorite et al. 2007; Picciau et al. 2019).

Gundelia L. (Asteraceae) is a genus of Irano-Turanian origin (Lev-Yadun and Abbo 1999) that for long time has been considered monospecific and represented only by $G$. tournefortii L., a thistle-like plant called "A'kub", "Akub" or "Akoub" in Arabic, very important in the ethnobotanical tradition of the East Mediterranean region. However, the recent discovery of new populations, particularly in Turkey and Armenia, highlighted a previously neglected interspecific variability (Vitek 2019). To date, Gundelia comprises 16 accepted species distributed in Afghanistan, Cyprus, Iran, Iraq, Lebanon, Jordan, Syria, Palestine, Sinai, Transcaucasus, Turkey, and Turkmenistan (POWO 2019), with its centre of diversity in Turkey (Vitek 2019). The young heads of $G$. tournefortii are mainly consumed as a fresh or cooked artichoke-like vegetable and the documented uses of this plant go back to more than 2000 years (Lev-Yadun and Abbo 1999) or even the Neolithic (Hind 2013). This plant has one of the most complicated inflorescence structures in the Asteraceae, which are reflected in its peculiar dispersal and seed germination mechanisms. The entire plant acts as a tumbleweed, while the fruit complexes (disseminules) thanks to their spiny tips-might stick to the fur of mammals, accomplishing further secondary dispersal (Karis et al. 2001). Plants present a thick perennial rootstock from which new growth arises each season (Lev-Yadun and Abbo 1999). Populations of this species can be found on rocky limestone or igneous slopes, steppes, open woodlands and sometimes as weed in fallow fields or roadside, from 100 to $2500 \mathrm{~m}$ a.s.l. (Hind 2013).

Despite its importance in the traditional diet and for the livelihoods of local communities in the whole
East Mediterranean region, plants are still mainly gathered for consumption from the wild (Lev-Yadun and Abbo 1999). No propagation methods are available in the literature (Owies et al. 2004) and this is probably due to the difficulties in cultivating these plants from seeds, as highlighted by previous studies on seed dormancy and germination requirements carried out on different populations of this species. However, this plant has been cultivated for the past two decades, both in Israel and in the Palestinian Authority, although the extent of its cultivation is still limited (LevYadun and Abbo 1999; Vitek et al. 2017). In addition, vegetative propagation trough division has also been suggested for this species, but no information is available on its success rate (Hind 2013).

Abu-Qaoud and Alkoni (1995) investigated the germination of disseminules collected near Nablus, in the West Bank territories. They obtained the highest germination percentage (48\%) when the fruits were extracted from the capitula after pre-soaking in water. They also reported that cold stratification at $4-5{ }^{\circ} \mathrm{C}$ didn't increase significantly the final germination. Owies et al. (2004) propagated this species in vitro, starting from plant material collected in the Jordan mountains at ca. $960 \mathrm{~m}$ a.s.l. They found that "seeds" were an effective starting material for in vitro culture. However, it is not clear if they worked with extracted fruits/seeds or with the whole disseminules. The best media for seed germination were agar-water and $1 / 4 \mathrm{MS}$ with $5.9 \mu \mathrm{M}$ gibberellic acid $\left(\mathrm{GA}_{3}\right)$, which after 4 weeks incubation at $24{ }^{\circ} \mathrm{C}$ led to 95 and $87 \%$ germination, respectively. The findings of Shibli et al. (2009), who worked on the same Jordan populations investigated by Owies et al. (2004), suggest that the highest germination percentages (nearly $90 \%$ after 4 weeks), are obtained by soaking the disseminules in a solution of $250 \mathrm{ppm} \mathrm{GA}$ for six hours, before sowing them under greenhouse conditions. Vaisi et al. (2018) found that mechanical scarification (suggesting that they worked with disseminules), together with gibberellic acid $1000 \mathrm{mg} / \mathrm{l}$ in six weeks stratification at $4{ }^{\circ} \mathrm{C}$, was the most influential treatment for seed dormancy breaking of this plant for populations collected in Iran at maximum altitudes of $2100 \mathrm{~m}$ a.sl. Finally, dried seed lots stored at the Kew's Millennium Seed Bank (constituted by disseminules) germinated at high germination percentages, with or without the removal of covering structures, when incubated in the range $10-20{ }^{\circ} \mathrm{C}$ (Royal Botanic Gardens Kew 2020). However, none of these studies considered the complex internal morphology of the dispersal units when they investigated and described the seed dormancy and germination of this species.

In this study, we investigated the seed germination responses of Mediterranean mountain populations of Gundelia tournefortii, comparing whole disseminules and extracted fruits, in order to understand how the peculiar morphology of the dispersal units of this species interact 
with the environmental conditions to control seed germination timing.

\section{Materials and methods}

\section{Seed lot details and experimental design}

Gundelia tournefortii L. inflorescence is a solitary, third order synflorescence of secondary capitula (the fruit complexes or disseminules), formed by the aggregation of 5-7 single-flowered primary capitula (Hind 2013). In each secondary capitulum, the floret of the central primary capitulum is hermaphrodite (but functionally female), while those of the subsidiary primary capitula are functionally male. All florets have brownish purple or yellow outside, and cream to bright yellow inside petals (Hind 2013). The fruit complex (i.e., the secondary capitulum or disseminule) is a turbinate cupule, which becomes woody with age, with the external compartments of male capitula becoming hollow (Hind 2013) (Fig. 1a-d). The strongly lignified disseminule contains a single enclosed cypsela (Fig. 1c-e) from the central capitulum, and the spiny, free tips of the phyllaries from all primary capitula function as an adhering, or protective pappus (Karis et al. 2001). The morphology of the cypsela must be considered in the light of the enclosure within the lignified capitulum (Fig. 1c, d), thus it is not surprising that neither the pericarp nor the testa are hard and protective (Karis et al. 2001).

Disseminules (Fig. 1) were collected from natural populations, by the staff of the Shouf Biosphere Reserve (Lebanon, Mount Lebanon Governorate) in July-August 2019, from eight different localities within the Reserve, for a total of 13 seed lots, as detailed in Table S1, at altitudes ranging from 1143 to $1672 \mathrm{~m}$ a.s.l., under a Mediterranean climate (Figure S1). Collected seed lots were then sent in October 2019 to the laboratory facilities of the Millennium Seed Bank (Royal Botanic Gardens, Kew) in the UK, where the different experiments were carried out, according to seed availability, as detailed below and summarized in Table S1. Internal structure of the secondary capitula (Fig. 1) was observed and analysed under a stereoscope (Leica 205c, Leica Microsystems, UK), equipped with a digital camera (DMC5400, Leica Microsystems, UK).

\section{Effect of $\mathrm{GA}_{3}$ on seed germination of capitula and extracted fruits}

Intact secondary capitula (Fig. 1a), hereafter "capitula" and fruits (Fig. 1e) extracted manually after $24 \mathrm{~h}$ imbibition of capitula on the top of a $1 \%$ agar-water solution to soften
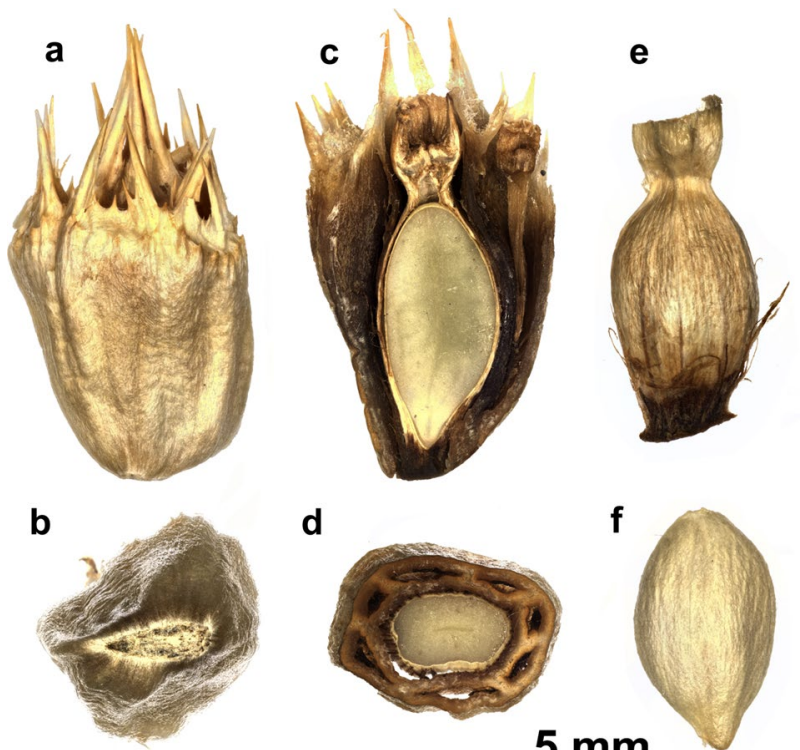

d
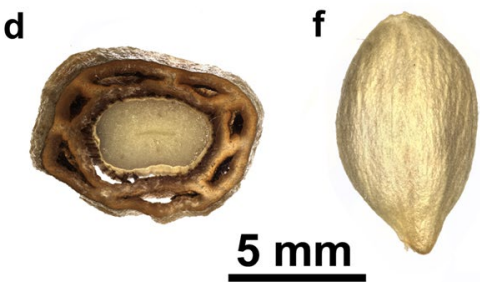

Fig. 1 Internal morphology of the secondary capitula (disseminules). a Longitudinal and $\mathbf{b}$ basal views. c Longitudinal section of the secondary capitulum showing the section of the cypsela (fruit), with the remnants of the hermaphrodite central floret on the top and the seed with the embryo inside. d Cross section of the secondary capitulum showing the clustering of the primary capitula around each floret, with the central one occupied by the cypsela and the external subsidiary ones, now hollow, where the male florets were located. e Longitudinal view of the fruit (cypsela). $\mathbf{f}$ Longitudinal view of the extracted seed

woody tissues, were incubated at $15{ }^{\circ} \mathrm{C}$ with a photoperiod of $12 \mathrm{~h}$ of irradiance per day and sown in plastic Petri dishes (three replicates of 20 units each for each investigated seed lot; Table S1), containing a $1 \%$ agar-water solution as germination substrate, with and without exogenous gibberellic acid $\left(\mathrm{GA}_{3} ; 250 \mathrm{mg} \mathrm{L}^{-1}\right)$ for 45 days, during which seed germination was scored daily. The incubation temperature of $15^{\circ} \mathrm{C}$ was chosen to mimic autumn season (see Fig. S1). At the end of the germination test, non-germinated capitula were kept for additional 15 days under incubation conditions (for a total of 60 days), scored for any additional germination and then opened manually to extract the fruits as described above and incubated at $15{ }^{\circ} \mathrm{C}$ under the same germination conditions for additional 45 days, in order to evaluate their viability. At the end of the germination experiments, nongerminated fruits were cut open to visually evaluate the embryo status (i.e., fresh, mouldy, or empty). This analysis highlighted less than $20 \%$ of empty capitula and less than $15 \%$ of empty fruits extracted from filled capitula in all investigated seedlots (Fig. 2). 


\section{Effect of cold stratification on seed germination of capitula}

Whole capitula (three replicates of 20 units each for each investigated seedlot; Table S1) were also sown on the top of germination substrate and incubated for a period of two months at $5{ }^{\circ} \mathrm{C}$, during which seed germination was scored weekly, before moving at $15^{\circ} \mathrm{C}$ and incubated as described above.

\section{Mechanical constraint analysis}

The resistance of the capitula to be pierced was measured in newton $(\mathrm{N})$, with a puncture force measuring system (Instron 5942 , UK) loaded with a 500N cell (Instron, UK) and a modified $160 \mu \mathrm{m}$ blunt probe attached to a pin vice. Up to ten capitula with viable seeds from each seed lot with available seeds (see Fig. S3) were used to assess the puncture force for dry capitula and after 2 days, 1 month and 2 months cold-wet incubation at $5{ }^{\circ} \mathrm{C}$. Samples consisted in the basal half of the capitula, with the seed removed. To allow the probe to pierce through the sample, these were fitted to a stainless-steel nut with $0.7 \mathrm{~cm}$ internal diameter (Figure S2a). Probe speed was set up to $1 \mathrm{~mm} / \mathrm{min}$ and applied force was recorded every tenth of a second in $\mathrm{N}$, down to four decimals using Bluehill Universal Software (Instron, UK) and the maximum force corresponding to the puncture event, assessed by visually analysing the curve of the applied force versus time (see Figure S2b for a schematization).

\section{Data analysis}

All analyses were carried out using $\mathrm{R}$ version 4.0.2 (R Core Team 2020) and all graphs plotted using the "ggplot2" (Wickham 2016) and "patchwork" (Pedersen 2020) packages.

Historic climatic data for the sampled localities were downloaded at a resolution of $30 \mathrm{~s}$. from the WorldClim v2 website (Fick and Hijmans 2017) and extracted using the "raster" package (Hijmans 2020).

Final germination percentage was assessed using the "GerminaR" package (Lozano-Isla et al. 2019), on the basis of the sown germinable seeds (i.e., excluding the empty ones) in each replicate.

The effect on seed germination of the type of dispersal unit (fruit or capitulum), the treatment (cold stratification or control) and of the application of exogenous $\mathrm{GA}_{3}$ were tested by Generalized Linear Mixed Models (GLMM) fitted by maximum likelihood (Laplace Approximation), with

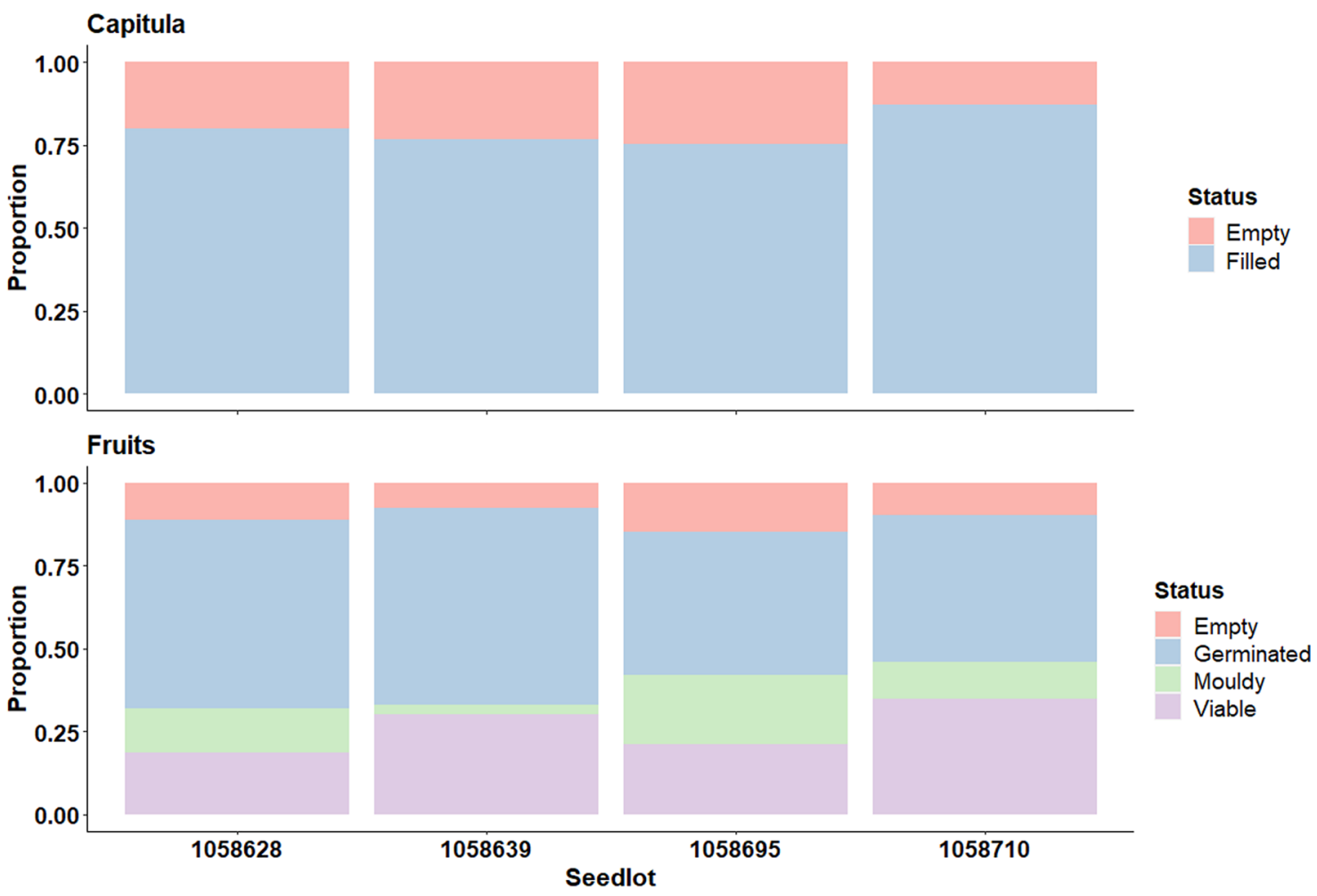

Fig. 2 Proportion of filled and empty capitula and fruits attributed to the different viability categories for each investigated seed lot 
seed lot as random factor, using the "glmer()" function of the "Ime4" package (Bates et al. 2015).

The effect of imbibition status of the capitula ("Status" as categorical variable with two levels: "dry" and "after 48 $h$ imbibition") and the length of their imbibition ("Time" as continuous variable in days) on the puncture force needed to pierce their basal area was analysed trough linear mixed models fitted by REML, with seed lot as random factor, using the "Imer()" function of the "Ime4" package (Bates et al. 2015).

\section{Results}

\section{Effect of $G A_{3}$ on germination of capitula and extracted fruits}

When incubated at $15^{\circ} \mathrm{C}$, the type of unit (whole secondary capitula or disseminules and extracted fruits) impacted significantly on the final germination proportion (Table 1 , Fig. 3). While, on average, capitula did not reach $20 \%$ of final germination either with or without the addition of exogenous $\mathrm{GA}_{3}$, extracted fruits reached $50 \%$ of germination, which increased to ca. $70 \%$ with $\mathrm{GA}_{3}$ (Fig. 3). Although the effect of the dispersal unit was identified as the main predictor in the model, the effect of $\mathrm{GA}_{3}$, but not their interaction, was also statistically significant (Table 1). Most seeds in the non-germinated capitula were still viable (ca. 90\%), as visually determined by the cut test carried out at the end of the experiments, and ca. half of them germinated when the fruits were extracted and incubated at $15{ }^{\circ} \mathrm{C}$ (Fig. 4).

\section{Effect of cold stratification on germination of capitula}

Cold stratification enhanced subsequent germination of the capitula to ca. 65\% (Fig. 5a and Table 2a). However almost half of the cold treated seeds germinated during the stratification at $5{ }^{\circ} \mathrm{C}$ with only the remnant ca. $15 \%$ of the initially sown capitula germinating during the subsequent incubation at $15{ }^{\circ} \mathrm{C}$ (Fig. 5b and Table 2b).

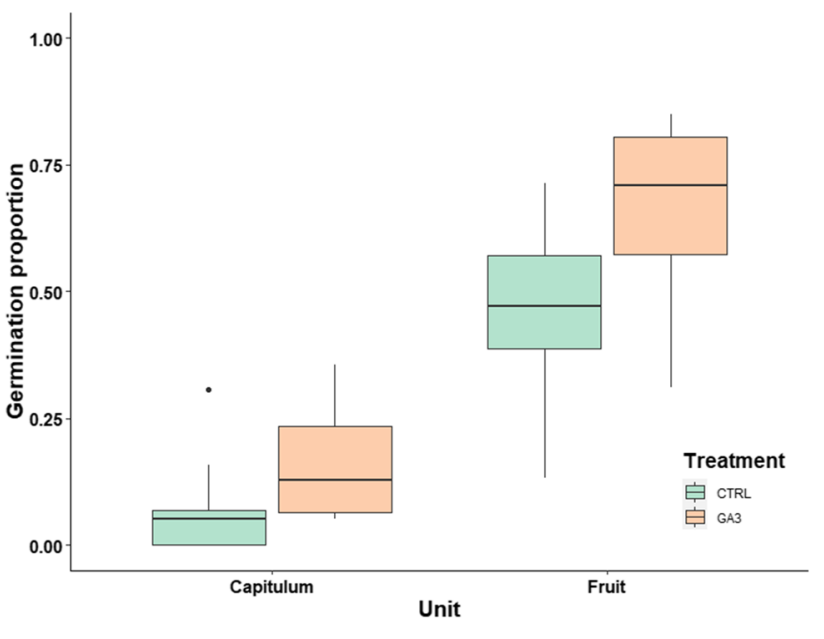

Fig. 3 Germination proportion of capitula and extracted fruits incubated at $15{ }^{\circ} \mathrm{C}$, with a photoperiod of $12 \mathrm{~h}$ of irradiance per day, with and without the application of exogenous $\mathrm{GA}_{3}$ on the germination substrate. Data are the mean of three replicates of 20 seeds each for each of the four investigated seed lots

\section{Mechanical constraint on seed germination}

An average peak puncture force of ca. $5 \mathrm{~N}$ was needed to pierce the basal part of the dry capitula (Fig. S3). Although the high variability among individual seeds on this initial value, which ranged from 1.4 to $11.9 \mathrm{~N}$ (Fig. S3), after $48 \mathrm{~h}$ imbibition, this value significantly dropped to ca. $0.7 \mathrm{~N}$ (min $0.3 \mathrm{~N}$ and max $1.3 \mathrm{~N}$; Fig. S3) (Fig. 6 and Table S2) and continued to decrease linearly during the cold stratification (ca. $-0.01 \mathrm{~N}$ per day; Table S3), until reaching the value of ca. 0.4 and ca. $0.2 \mathrm{~N}$ at the end of one and two months, respectively (Fig. 6).

All seedlots started germinating after one month in the 30-37 days interval (Fig. 6 and Fig. S4), which corresponded to peak puncture force values comprised between 0.41 and $0.35 \mathrm{~N}$ (Fig. 6).

Table 1 Generalized linear mixed model fitted by maximum likelihood (Laplace Approximation) for the effect of unit (Capitulum or Fruit) and $\mathrm{GA}_{3}$ application (fixed factors) on seed germination for the investigated seed lots (random factor)

\begin{tabular}{lrrrrr}
\hline & Estimate & Std. Error & z value & CI 2.5\% & CI 97.5\% \\
\hline Intercept & -2.7164 & 0.3221 & -8.433 & -3.4039782 & -2.1118904 \\
Fruit & 2.5949 & 0.3318 & 7.821 & 1.9799597 & 3.2910285 \\
GA3 & 0.9916 & 0.3611 & 2.746 & 0.3063193 & 1.7342646 \\
Fruit*GA3 & -0.1192 & 0.4178 & -0.285 & -0.9632769 & 0.6835553 \\
\hline
\end{tabular}

Confidence intervals that do not cross zero confirm the validity of the estimate. logLik: -95.6 ; deviance: 191.2 ; df resid: 43 . Random effect variance: $0.05796 \pm 0.2408$ 


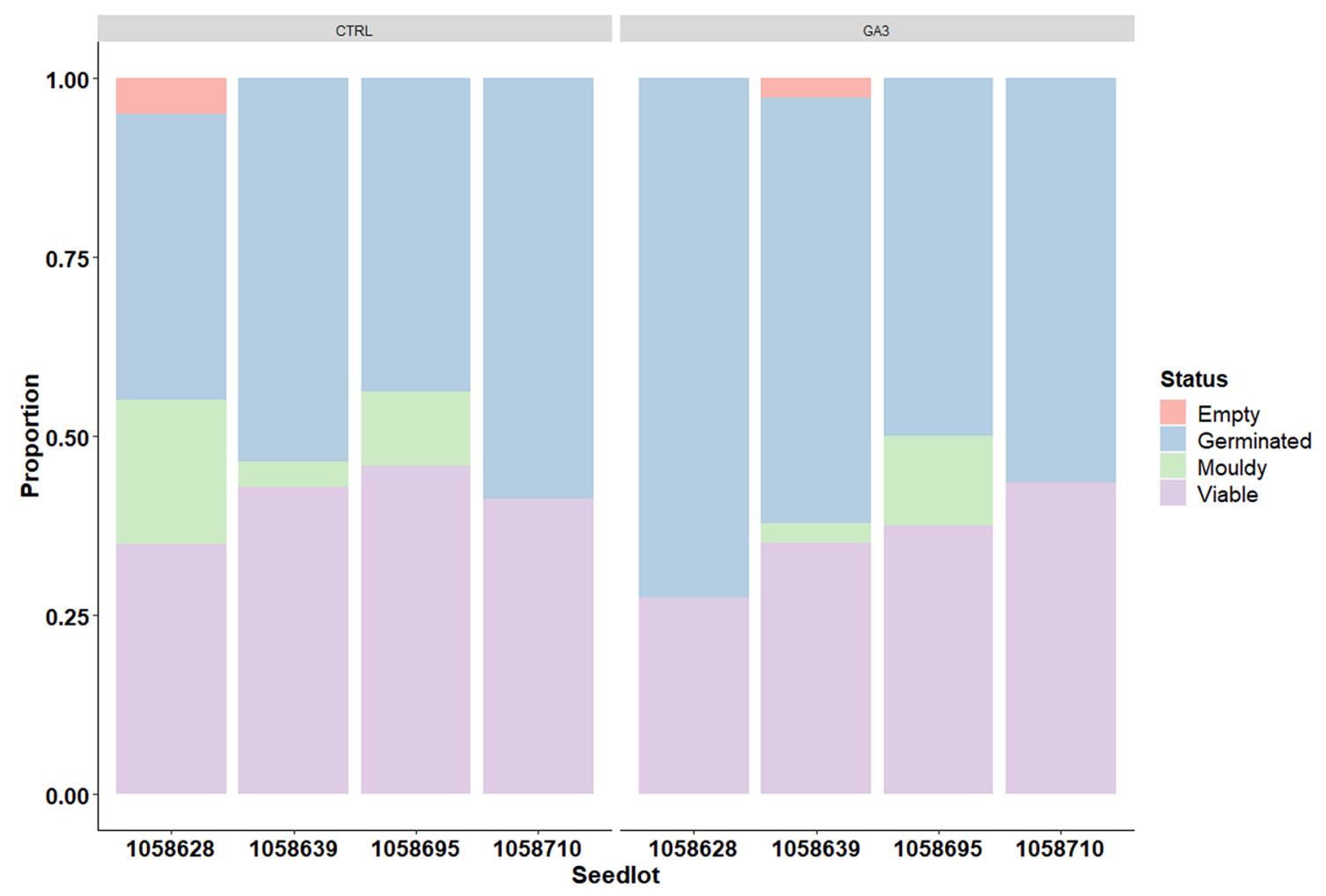

Fig. 4 Seed germination results of fruits extracted from ungerminated capitula at the end of the germination experiments presented in Fig. 2

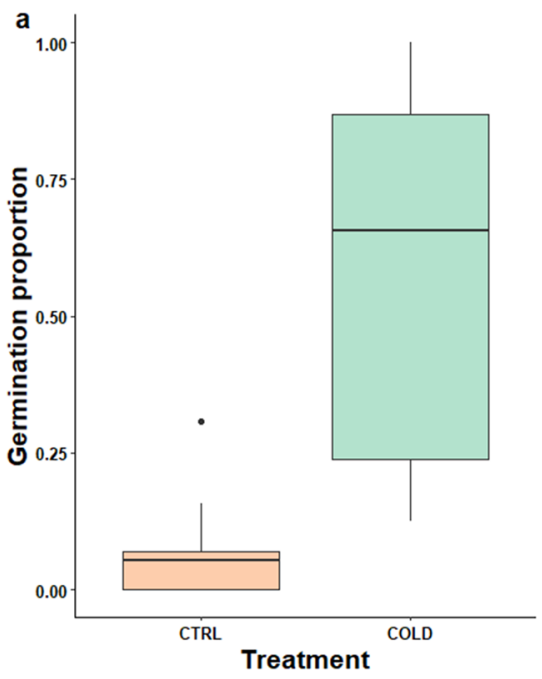

Fig. 5 a Germination proportion of capitula incubated at $15{ }^{\circ} \mathrm{C}$ with (COLD) or without (CTRL) a previous incubation period of two months at $5{ }^{\circ} \mathrm{C}$. For the cold treatment, the germination proportion at $15{ }^{\circ} \mathrm{C}$ is calculated on the basis of the seeds that did not germinate during the cold stratification. b Germination proportion of the two

\section{Discussion}

In seed germination ecology studies, it is recommended to use the intact natural dispersal units (i.e., the fruit or seed

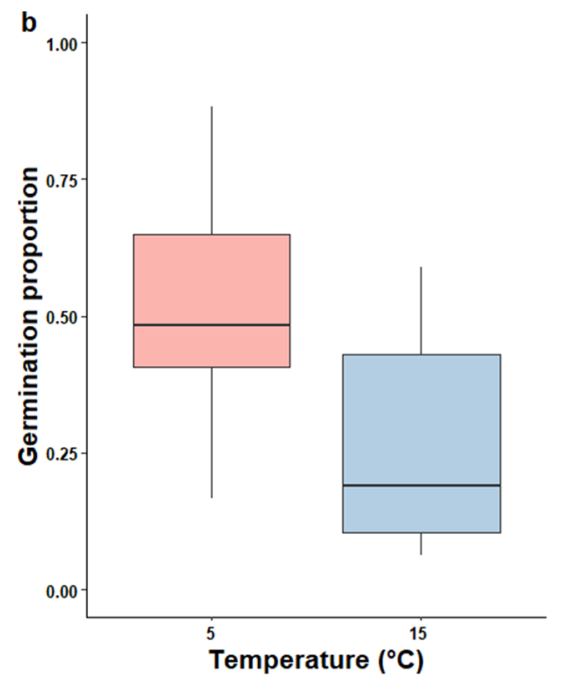

steps (i.e., incubation at 5 and $15^{\circ} \mathrm{C}$ ) in the cold treatment calculated on the basis of the total number of filled seeds sown at the beginning of the experiment. Data are the mean of three replicates of 20 seeds each for each of the four investigated seedlots

in the form in which it would normally occur in nature after dispersal), because removal of parts from it may increase/decrease germination percentages (Baskin et al. 2007). In Gundelia tournefortii, these are the lignified 
Table 2 Generalized linear mixed models fitted by maximum likelihood (Laplace Approximation) on the effect on seed germination of (a) treatment (control or cold stratification) and (b) different incubation steps during the cold treatment for the investigated seed lots (random factor)

\begin{tabular}{|c|c|c|c|c|c|}
\hline & Estimate & Std. Error & $\mathrm{z}$ value & CI $2.5 \%$ & CI $97.5 \%$ \\
\hline \multicolumn{6}{|l|}{ (a) } \\
\hline Intercept & -2.8635 & 0.4824 & -5.936 & -4.0676600 & -1.786457 \\
\hline \multicolumn{6}{|l|}{ (b) } \\
\hline Intercept & -1.0422 & 0.2062 & -5.055 & -1.5308554 & -0.593787 \\
\hline Step $5^{\circ} \mathrm{C}$ & 1.1539 & 0.2242 & 5.146 & 0.7192044 & 1.599514 \\
\hline
\end{tabular}

Confidence intervals that do not cross zero confirm the validity of the estimate. (a) logLik: -46.0 ; deviance: 92.1 ; df resid: 21 . Random effect variance: $0.5346 \pm 0.7312$. (b) $\operatorname{logLik}:-64.1$; deviance: 128.2 ; df resid: 21 . Random effect variance: $0.05581 \pm 0.2362$

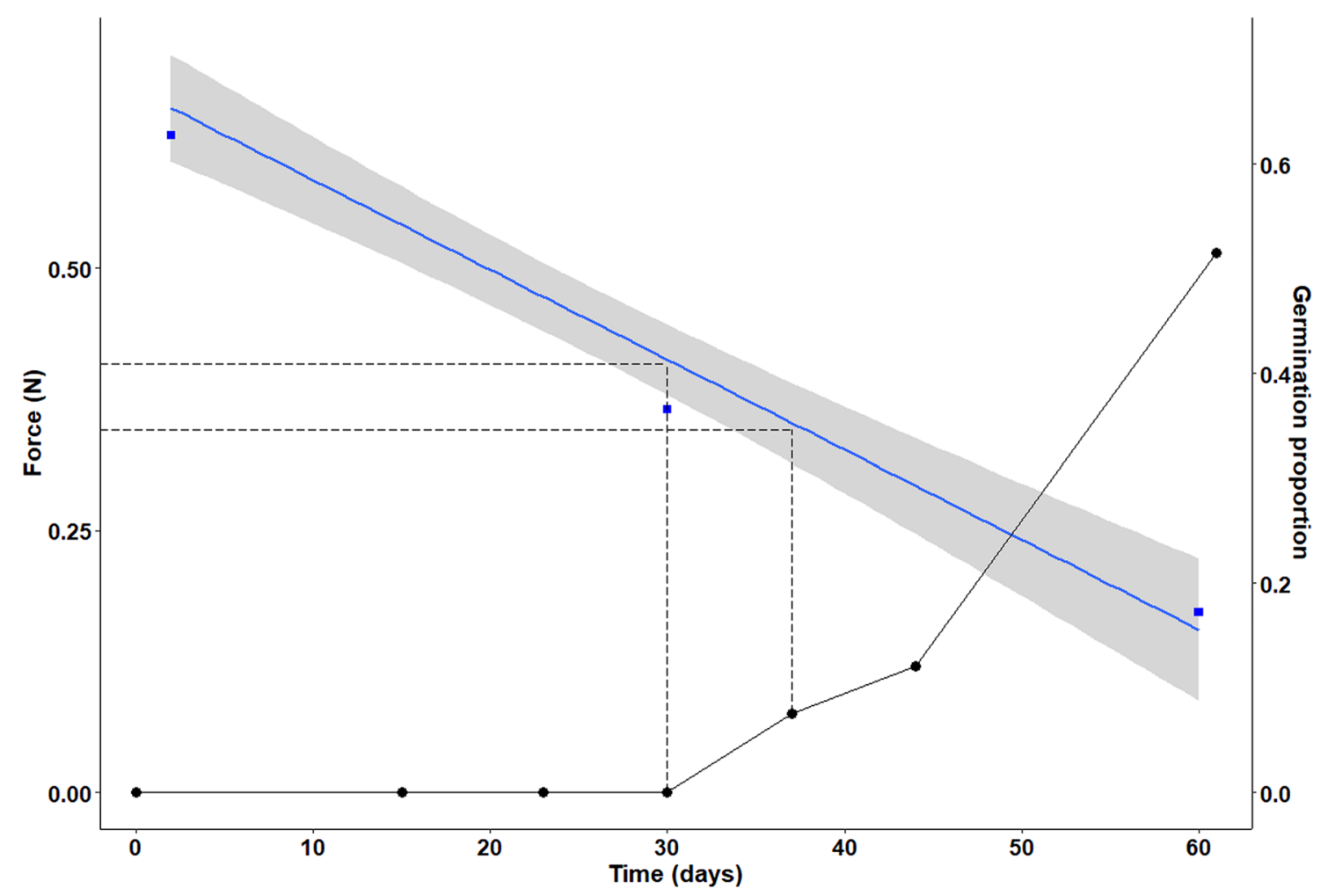

Fig. 6 Puncture force needed to pierce the basal part of the capitula and germination of the capitula after 2 days, 1 month and 2 months of cold-wet incubation at $5{ }^{\circ} \mathrm{C}$. Blue squares represent the mean puncture force at each measurement time and blue line represents the fitted

secondary capitula, or disseminules, which constitute a morphological unicum with the enclosed cypsela, whose pericarp is not hard nor protective (Karis et al. 2001).

Previous reports on seed germination of G. tournefortii suggest the presence of a physiological seed dormancy sensu Baskin and Baskin (2014) for this species. Abu-Qaoud and Alkoni (1995) found that concentrated sulfuric acid for 15 or $30 \mathrm{~min}$, as well as cold stratification did not increase seed germination of low altitude populations, while other linear model for the puncture force (see Table S3 for equation parameters). Black points represent the mean cumulative germination of the cold stratified capitula (see also Figures S3 and S4 for details of each seed lots)

authors found a significant positive effect of gibberellic acid (Owies et al. 2004; Shibli et al. 2009; Vaisi et al. 2018) and cold stratification (Vaisi et al. 2018) on seed germination of mountain populations. The very low germination percentages reached at $15{ }^{\circ} \mathrm{C}$ in our study by the disseminules treated with gibberellic acid $\left(\mathrm{GA}_{3}\right)$, compared to the relatively high germination proportion achieved by the extracted fruits even without $\mathrm{GA}_{3}$, highlights the presence of mechanical constraints on embryo growth and radicle protrusion. 
This was confirmed by the decreasing of the resistance to piercing of the capitula during cold stratification at $5{ }^{\circ} \mathrm{C}$, which after a month, almost halved their value of peak puncture force for imbibed capitula and the disseminules started germinating. At the same time, the significant positive effect of the application of $\mathrm{GA}_{3}$ on seed germination of extracted fruits, although not as statistically important as the effect of the type of dispersal unit (i.e., the mechanical constraint from the capitulum) as assessed by the generalized linear mixed model, also highlighted the presence of a hormonal constraint to seed germination. Therefore, we can identify the presence of physiological seed dormancy constituted by both a mechanical (capitulum-imposed) and hormonal (embryo) component, with the first being prominent. This dormancy is broken by incubation at cold temperatures, which reduces the mechanical constraint associated with the capitulum layers, while increasing the embryo growth potential (hormonal constraint), by triggering the endogenous $\mathrm{GA}_{3}$ synthesis (Baskin and Baskin 2014).

The ability of 1-month-cold-stratified intact disseminules to germinate at high proportions without the need to add exogenous hormones such as $\mathrm{GA}_{3}$, or to apply laborious and time consuming methods to extract the fruits, could help local farmers in Lebanon to develop plant propagation protocols and support the shift from the mass consumption of this plant from material gathered in the wild to its cultivation, relieving the pressure from natural populations, as auspicated by Lev-Yadun and Abbo (1999).

Disseminules of the mountain populations investigated in this study were ready to be collected (and we can therefore assume that this is also the period of natural dispersal) during the dry summer (July-August), when according to the historical climatic data of the investigated populations (Fick and Hijmans 2017) precipitation are null and mean temperatures are above $20^{\circ} \mathrm{C}$. If this species was going to adhere to the "typical Mediterranean germination syndrome" (Doussi and Thanos 2002; Thanos et al. 1989, 1991, 1995), disseminules would be expected to start germinating in autumn, when rainfall starts increasing and average temperatures drop below $15{ }^{\circ} \mathrm{C}$. On the contrary, if they were to follow a typical alpine germination strategy (FernándezPascual et al. 2021), they would start germinating in spring, after a cold stratification period over winter that would break seed dormancy. Warm-cued germination in spring after cold stratification was previously reported for other Mediterranean mountain species (Picciau et al. 2019; Skordilis and Thanos 1995), including Lamyropsis microcephala (Asteraceae) (Mattana et al. 2009), an Asteraceae species endemic of the Gennargentu massif (Sardinia, Italy), which belongs to a genus with a main eastern Mediterranean distribution (Greuter and Dittrich 1973).

When incubated at $15{ }^{\circ} \mathrm{C}$ disseminules failed to germinate, excluding autumn germination. In addition, although two months of cold stratification enhanced subsequent germination at $15{ }^{\circ} \mathrm{C}$, ca an half of the sown capitula were germinated at the end of the cold stratification. Only one month at $5{ }^{\circ} \mathrm{C}$ was required to release physiological dormancy and disseminules started germinating straight away during the second month of cold stratification, without waiting for a rise in environmental temperatures to trigger germination as for typical warm-cued alpine plants (Fernández-Pascual et al. 2021). These findings are consistent with a field germination of the dispersed disseminules in December-January, when mean temperatures in the natural populations are around 5 ${ }^{\circ} \mathrm{C}$ and rainfall is at his annual maximum, well ahead of the summer droughts starting in April-May.

The mechanical and hormonal constraints delay germination to winter in order to avoid autumn germination which —at these altitudes—would lead to frost damage over winter for the newly established seedlings and at the same time allow early winter germination in order to extend as much as possible the seedling establishment phase, before the onset of the summer droughts. However, it should be considered that this plant can be found also at low altitudes (Hind 2013). Thus, it is possible that this species could show phenotypic plasticity to temperature and vary its seasonal germination niche across populations, as previously reported along an altitudinal cline for other Mediterranean plants, such as Streptanthus tortuosus in California (Gremer et al. 2020). Therefore, considering that this study only focused on mountain poulations of this species at altitudes comprised between 1181 and $1672 \mathrm{~m}$ a.s.l., further studies should be carried out to understand the intraspecific genetic and ecological variability of this species, covering the whole altitudinal gradient, as well as different geographic regions, of the species distribution. In addition, considering the perennial habit of this plant, the role of vegetative propagation in perpetuating the present populations on the top of their reproduction by seed, should also be investigated.

\section{Conclusions}

The findings of this study highlight the presence of physiological seed dormancy sensu Baskin and Baskin (2014) with a mechanical (capitulum-imposed) and hormonal (embryo) component. The peculiar morphology of the synflorescence and disseminules controls seed germination timing, by interacting with environmental conditions of the mountain populations under a Mediterranean climate, avoiding autumn but allowing early winter seed germination. These findings not only provide new insights on the reproductive biology and ecology of this species, but can also support local farmers develop plant propagation programmes for the cultivation of this key wild edible species, important for food security 
and the livelihoods of local communities in the whole East Mediterranean region.

Supplementary Information The online version contains supplementary material available at https://doi.org/10.1007/s10725-021-00717-5.

Acknowledgements We would like to thank the staff of the Lebanese Agricultural Research Institute (LARI), in particular the Seed Bank Manager Ms. Joêlle Breidy, for their support and facilitating the collection of the seeds. The Shouf Biosphere Reserve team, in particular Eng. Nijad Saad Eddine collected the seed material in Lebanon and Eng. Khaled Sleem provided information on their local propagation trials. David Coleshill and Giulio Barone helped with the seed germination scoring and Jemma Taylor with the project management and logistics at RBG Kew (UK).

Author contributions All authors contributed to the conception of the study. EM designed the experiments. EM and PGB conducted the experiments and collected the data. EM analysed the data. EM wrote the first draft of the manuscript with critical revisions by all authors. All authors read and approved the final manuscript.

Funding This study was funded by the "Project MGU-the Useful Plants Project", as part of the pilot project "ResMed-Restoring the traditional Mediterranean diet through the conservation of wild edible plants" in Jordan and Lebanon. Efisio Mattana is supported by the Kew Future Leaders Fellowship - Diversity and Livelihoods, from the Royal Botanic Gardens, Kew.

Data availability The raw dataset generated and analysed during the current study are available from the corresponding author on reasonable request.

\section{Compliance with ethical standards}

Conflict of interest The authors have no relevant financial or non-financial interests to disclose.

Open Access This article is licensed under a Creative Commons Attribution 4.0 International License, which permits use, sharing, adaptation, distribution and reproduction in any medium or format, as long as you give appropriate credit to the original author(s) and the source, provide a link to the Creative Commons licence, and indicate if changes were made. The images or other third party material in this article are included in the article's Creative Commons licence, unless indicated otherwise in a credit line to the material. If material is not included in the article's Creative Commons licence and your intended use is not permitted by statutory regulation or exceeds the permitted use, you will need to obtain permission directly from the copyright holder. To view a copy of this licence, visit http://creativecommons.org/licenses/by/4.0/.

\section{References}

Abu-Qaoud H, Alkoni RD (1995) The effect of different seed treatments on seed germination of Gundelia tournefortii seeds. AnNajah J Res 3:58-72

Baskin CC, Baskin JM (2014) Seeds: ecology, biogeography, and evolution of dormancy and germination, 2nd edn. Elsevier, Amsterdam
Baskin CC, Thompson K, Baskin MJ (2007) Mistakes in germination ecology and how to avoid them. Seed Sci Res 16:165-168. https:// doi.org/10.1079/SSR2006247

Bates D, Maechler M, Bolker B, Walker S (2015) Fitting linear mixedeffects models using lme4. J Stat Softw 67:1-48

Chen S-C, Poschlod P, Antonelli A, Liu U, Dickie JB (2020) Trade-off between seed dispersal in space and time. Ecol Lett 23:16351642. https://doi.org/10.1111/ele.13595

Doussi MA, Thanos CA (2002) Ecophysiology of seed germination in Mediterranean geophytes. 1. Muscari Spp. Seed Sci Res 12:193201. https://doi.org/10.1079/SSR2002111

Fernández-Pascual E et al (2021) The seed germination spectrum of alpine plants: a global meta-analysis. New Phytol 229:3573-3586. https://doi.org/10.1111/nph.17086

Fick SE, Hijmans RJ (2017) WorldClim 2: new 1-km spatial resolution climate surfaces for global land areas. Int J Climatol 37:43024315. https://doi.org/10.1002/joc.5086

Finch-Savage WE, Leubner-Metzger G (2006) Seed dormancy and the control of germination. New Phytol 171:501-523. https://doi.org/ 10.1111/j.1469-8137.2006.01787.x

Giménez-Benavides L, Escudero A, Pérez-García F (2005) Seed germination of high mountain Mediterranean species: altitudinal, interpopulation and interannual variability. Ecol Res 20:433-444. https://doi.org/10.1007/s11284-005-0059-4

Gremer JR, Chiono A, Suglia E, Bontrager M, Okafor L, Schmitt J (2020) Variation in the seasonal germination niche across an elevational gradient: the role of germination cueing in current and future climates. Am J Bot 107:350-363. https://doi.org/10. 1002/ajb2.1425

Greuter W, Dittrich M (1973) Neuer Beitrag zur Kenntnis der Gattung Lamyropsis (Compositae): die Identitat von Cirsium microcephalum Moris. Ann Mus Goulandris 1:85

Hijmans RJ (2020) Geographic data analysis and modeling [R package raster version 3.3-13]

Hind N (2013) 763. Gundelia tournefortii. Curtis Bot Mag 30:114-138. https://doi.org/10.1111/curt.12027

Karis PO, Eldenäs P, Källersjö M (2001) New evidence for the systematic position of Gundelia L. with notes on delimitation of Arctoteae (Asteraceae). Taxon 50:105-114. https://doi.org/10. 2307/1224514

Lev-Yadun S, Abbo S (1999) Traditional Use of A'kub (Gundelia tournefortii, Asteraceae), in Israel and the Palestinian Authority Area. Econ Bot 53:217-219

Lorite J, Ruiz-Girela M, Castro J (2007) Patterns of seed germination in Mediterranean mountains: study on 37 endemic or rare species from Sierra Nevada. SE Spain Candollea 62:5

Lozano-Isla F, Benites-Alfaro OE, Pompelli MF (2019) GerminaR: an $\mathrm{R}$ package for germination analysis with the interactive web application "GerminaQuant for R." Ecol Res 34:339-346

Mattana E, Daws MI, Bacchetta G (2009) Seed dormancy and germination ecology of Lamyropsis microcephala: a mountain endemic species of Sardinia (Italy). Seed Sci Technol 37:491-497. https:// doi.org/10.15258/sst.2009.37.2.24

Owies DS, Shibli RA, Ereifej KI (2004) In vitro propagation of Gundelia tournefortii L. Adv Hortic Sci 18:127-131

Pedersen TL (2020) Patchwork: the composer of plots. R package version 1.0.1. https://CRAN.R-project.org/package $=$ patchwork

Picciau R, Pritchard HW, Mattana E, Bacchetta G (2019) Thermal thresholds for seed germination in Mediterranean species are higher in mountain compared with lowland areas. Seed Sci Res 29:44-54. https://doi.org/10.1017/S0960258518000399

Poschlod P, Abedi M, Bartelheimer M, Drobnik J, Rosbakh S, Saatkamp A (2013) Seed ecology and assembly rules in plant communities. In: van der Maarel E, Franklin J (eds) Vegetation ecology. Wiley, New York, pp 164-202. https://doi.org/10.1002/97811 18452592.ch6 
POWO (2019) Plants of the world online. Facilitated by the Royal Botanic Gardens, Kew. http://www.plantsoftheworldonline.org/. Accessed 02 Nov 2020

R Core Team (2020) R: a language and environment for statistical computing. R Foundation for Statistical Computing, Vienna

Royal Botanic Gardens Kew (2020) Seed information database (SID). Version 7.1. (2020) http://data.kew.org/sid/. Accessed 04 Nov 2020

Shibli RA, Oweis DS, Eriefej KI, Sc Shatnawi M (2009) In vivo propagation of Akub (Gundelia trournefortii L.) by seeds Jordan. J Agric Sci 5:266-272

Skordilis A, Thanos CA (1995) Seed stratification and germination strategy in the Mediterranean pines Pinus Brutia and P. Halepensis Seed Sci Res 5:151-160. https://doi.org/10.1017/S096025850 0002774

Sperber K et al (2017) Fruit fracture biomechanics and the release of Lepidium didymum pericarp-imposed mechanical dormancy by fungi. Nat Commun 8:1868. https://doi.org/10.1038/ s41467-017-02051-9

Steinbrecher T, Leubner-Metzger G (2016) The biomechanics of seed germination. J Exp Bot 68:765-783. https://doi.org/10.1093/jxb/ erw428
Thanos CA, Georghiou K, Skarou F (1989) Glaucium flavum seed germination-an ecophysiological approach. Ann Bot 63:121-130. https://doi.org/10.1093/oxfordjournals.aob.a087714

Thanos CA, Georghiou K, Douma DJ, Marangaki CJ (1991) Photoinhibition of seed germination in mediterranean maritime plants. Ann Bot 68:469-475. https://doi.org/10.1093/oxfordjournals.aob.a088280

Thanos CA, Kadis CC, Skarou F (1995) Ecophysiology of germination in the aromatic plants thyme, savory and oregano (Labiatae). Seed Sci Res 5:161-170. https://doi.org/10.1017/S0960258500002786

Vaisi G, Mohtadi A, Moradi A (2018) The effect of different treatments on seed germination and dormancy breaking in seeds of Gundelia tournefortii. Nova Biol Reperta 5:26-37

Vitek E (2019) Gundelia (Compositae), from one to many species-an ignored diversity. Flora Medit 28:307-313

Vitek E, Leschner H, Armağan M (2017) Gundelia tournefortii L. (Compositae)_an approach Annalen des Naturhistorischen Museums in Wien Serie B für. Bot Und Zool 119:227-234

Wickham H (2016) ggplot2: elegant graphics for data analysis. Springer, Berlin

Publisher's Note Springer Nature remains neutral with regard to jurisdictional claims in published maps and institutional affiliations. 